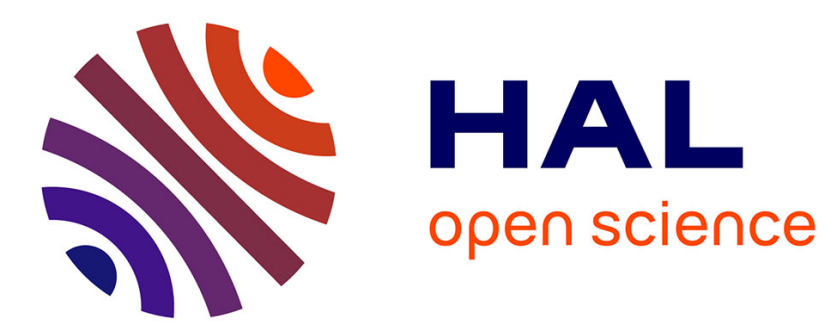

\title{
Association between fetal DES-exposure and psychiatric disorders in adolescence/adulthood: evidence from a French cohort of 1002 prenatally exposed children
} Marie-Odile Soyer-Gobillard, Françoise Paris, Laura Gaspari, Philippe Courtet, Charles Sultan

\section{To cite this version:}

Marie-Odile Soyer-Gobillard, Françoise Paris, Laura Gaspari, Philippe Courtet, Charles Sultan. Association between fetal DES-exposure and psychiatric disorders in adolescence/adulthood: evidence from a French cohort of 1002 prenatally exposed children. Gynecological Endocrinology, 2016, 32 (1), pp.25-29. 10.3109/09513590.2015.1063604 . hal-01890357

\section{HAL Id: hal-01890357 https://hal.science/hal-01890357}

Submitted on 28 Oct 2019

HAL is a multi-disciplinary open access archive for the deposit and dissemination of scientific research documents, whether they are published or not. The documents may come from teaching and research institutions in France or abroad, or from public or private research centers.
L'archive ouverte pluridisciplinaire HAL, est destinée au dépôt et à la diffusion de documents scientifiques de niveau recherche, publiés ou non, émanant des établissements d'enseignement et de recherche français ou étrangers, des laboratoires publics ou privés. 
Association between fetal DES-exposure and psychiatric disorders in adolescence/adulthood: evidence from a French cohort of 1002 prenatally exposed children.

Marie-Odile SOYER-GOBILlaRD*, Ph.D., Françoise PARIS***, M.D., Ph.D., Laura GASPARI***, M.D., Philippe COURTET**, M.D., Ph. D., and Charles SUlTAN***, M.D., Ph.D.

*Centre National de la Recherche Scientifique, Unité Mixte de Recherche 7628, Université Paris 6 and Association HHORAGES-France, 95270 Asnières sur Oise, France

**Département d'Urgence et Post Urgence Psychiatrique, CHU Montpellier \& Université Montpellier, France

***Unité d'Endocrinologie-Gynécologie Pédiatrique, Service de Pédiatrie, Hôpital Arnaud de Villeneuve, CHU Montpellier and Université Montpellier, France

Corresponding author: Dr MO Soyer-Gobillard, 78 Avenue Guynemer, F-66100 Perpignan, France

mog66@orange.fr 


\section{Summary}

In utero DES exposure has been demonstrated to be associated with somatic abnormalities in adult men and women. Conversely, the data are contradictory regarding the association with psychological or psychiatric disorders during adolescence and adulthood.

This work was designed to determine whether prenatal exposure to DES affects brain development and whether it is associated with psychiatric disorders in male and female adolescents and young adults. HHORAGES Association, a national patient support group, has assembled a cohort of 128201282 women who took DES during pregnancy. We obtained questionnaire responses from 529 families, corresponding to 1182 children divided into three groups: Group $1(\mathrm{n}=180)$ : firstborn children without DES treatment, Group $2(\mathrm{n}=740)$ : exposed children, and Group $3(n=262)$ : children born after a previous pregnancy treated by DES.

No psychiatric disorders were reported in Group 1. In Group 2, the incidence of disorders was drastically elevated (83.8\%), and in Group 3, the incidence was still elevated (6.1\%) compared with the general population.

This work demonstrates that prenatal exposure to DES is associated with a high risk of psychiatric disorders in adolescence and adulthood.

Key words: Prenatal DES exposure, Psychiatric disorders, Suicide, Adolescence, Adulthood. 


\section{Introduction}

From the 1950s to the late 1970s, millions of women took diethylstilbestrol (DES) during pregnancy to prevent miscarriages and premature births, to inhibit the milk inflow after childbirth, or to treat infertility, primary or secondary amenorrhea, dysmenorrhea and other genital disorders (Smith 1948). Strikingly, DES continued to be used despite various alerts that were published as early as 1940 (1) and the demonstration of Diekmann et al. (2) that DES was ineffective in preventing miscarriage or premature birth. In 1971, it emerged that in utero DES exposure was associated with somatic effects in adulthood, including female genital abnormalities $(3,4)$, vaginal cancer (5), and male urogenital disorders (6). In experimental studies, mice exposed to DES during gestation were found to be more aggressive than controls (7), and the offspring of rats treated by intraperitoneal administration of another synthetic estrogen, ethinylestradiol (EE), were shown to present altered emotional states like anxiety and depressive-like behaviors $(8,9)$. In humans, only three large epidemiological studies $(10,11,12)$ and seven studies on a small number of exposed subjects (as summarized in the critical review of Kebir and Krebs) (13) have pointed out a risk of psychological or psychiatric disorders during adolescence or post-adolescence after in utero DES exposure. However, the data are discrepant (11) regarding the impact of DES on the developing fetal brain and the consequences for adolescents and adults. The aim of this work was to determine whether prenatal exposure to DES can induce psychological and/or psychiatric disorders in teenagers and young adults.

\section{Materials and methods: The HHORAGES cohort}

The HHORAGES Association (Halt to Synthetic Hormones for Pregnancies), a patient support group, has assembled a cohort of 1280 women who took DES during pregnancies. A detailed questionnaire (Table 1) was prepared and validated by researchers and doctors and sent to these families. As psychiatric diseases generally appear in the post-adolescent period, after 18 years, the 
questionnaire concerned people born between 1946 and 1995. An authorization request was sent to the French "Commission Nationale de l'Informatique et des Libertés" (CNIL), which authorized the use of the questionnaire. We included items on patient sex, rank among siblings, specific exposure during gestation (DES alone or in association with EE), and somatic and psychiatric disorders.

Out of these 1280 families, 529 families responded to this extensive questionnaire, providing information on the family history; the mother's hormone treatment before and during pregnancy; medical records, including prescriptions; and the health problems of the children, including diagnoses and any medical treatments or hospitalizations. The psychiatric disorders reported in the questionnaires were classified as: eating disorders, behavioral disorders, obsessivecompulsive disorders, depression and bipolar disorders, schizophrenia, and suicides (attempts, death). When suicides or suicide attempts were reported, a second questionnaire validated by members of the Research Group on Suicide (CHU Lapeyronie Montpellier) was sent to the families.

\section{Results}

The results are presented in Table 2.

We collected completed questionnaires from 529 families, corresponding to 1182 children. Among these 1182 children, 180 firstborn children without DES exposure served as intrafamilial controls (Table 2). The analysis was conducted according to specific descriptive criteria: treatment by synthetic xenohormones (DES, EE), exposed and unexposed children, patient sex, birth order rank, and somatic and psychiatric disorders.

Of the 1182 children (552 sons +630 daughters) born from 529 mothers, we noted that 180 of them (102 sons +78 daughters) were born without any DES exposure, before a DES-exposed pregnancy. We named this group "Pre-DES" (Group 1). 740 children (315 boys +405 
daughters +20 stillborn) were born after DES exposition, this synthetic estrogen (banned only in 1977 in France) having been prescribed alone or in combination with ethinylestradiol (EE), we called this group "DES exposed" (Group 2). The third group was composed of the 262 children (130 sons +132 daughters) born from a mother that had taken DES for a previous pregnancy: we named this group "Post-DES" (Group 3) (Table 2). In total, 1002 children were exposed (740 children exposed under prescription plus 262 Post-DES children, i.e., born after a previous pregnancy treated with DES).

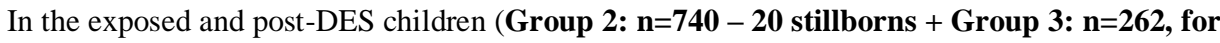
a total of 982) we found that 603 children from Group 2 (250 sons +353 daughters) and 16 from Group 3 were affected by psychiatric disorders (Table 2), in addition to 81 children with genital malformation and/or sterility but no apparent psychiatric disorders. In Group 2, 70 children were without any disorder and in Group 3, 242 children were without disorder.

For the 250 boys, psychiatric disorders were determined on the basis of family testimonies or medical records of antipsychotic or antidepressant prescription and/or psychiatric hospitalization, as follows: behavioral disorders, violence, aggressiveness, and obsessivecompulsive disorders $(n=47)$, eating disorders $(n=6)$, schizophrenia $(n=112)$, and depression, bipolar disorder and anxiety $(\mathrm{n}=85)$, with schizophrenia being the most prevalent pathology. For the 353 girls, psychiatric disorders were as follows: behavioral disorders and obsessivecompulsive disorders $(n=62)$, eating disorders $(n=75)$, schizophrenia $(n=53)$, and recurrent depressive or bipolar disorders ( $\mathrm{n}=163)$, with affective disorders being the most prevalent.

Among the 262 post-DES cases, 16 of them $(6.1 \%)$ presented psychiatric disorders and only four presented somatic disorders (4 girls). Among the 16 subjects presenting psychiatric disorders, one suffered behavioral disorders, six presented schizophrenia ( 3 boys +3 girls), and 
nine presented bipolar disorders and depression ( 3 boys +6 girls); among them, one suicide and five suicide attempt series were noted.

From the 1182 children of our cohort, 180 firstborns were unexposed (102 firstborn boys +78 firstborn girls): none of these firstborns presented any disorders, had ever made a suicide attempt or had committed suicide. Conversely, among the 982 exposed and post-DES children (1002 minus the 20 stillborns), we noted 33 suicides ( 24 sons +9 daughters) and 107 series of suicide attempts (42 sons +65 daughters), a series comprising between two and 15 suicide attempts per person. Thus, if we assume that the mean number of suicide attempts was six per person, about 642 suicide attempts were made (Table 3). The psychological and/or psychiatric disorders are presented in Table 4 along with the prevalences for these disorders in the general population $(14,15)$.

\section{Discussion}

Very few studies have investigated the impact of prenatal exposure to DES or synthetic hormones on psychiatric outcome. Up to now, most of the studies have been carried out on rodents and have shown the toxic effects of synthetic estrogens on the descendants, particularly in terms of behavioral disorders, as well as other effects like cancers (16), with multigenerational carcinogenic effects in mice (17). Injection of 17-alpha-ethinyloestradiol (EE) in pregnant rats induces not only a high rate of abortion, but also anxiety and depression-type disorders in pups $(8,9)$. Based on these findings, it is hypothesized that estrogenic hormones induce neurodevelopmental disturbances in exposed human subjects and may potentially mediate an increased risk of behavioral and psychiatric disorders. Although selection biases (family association) may somewhat affect the impact of our data, the high prevalence of psychiatric disorders in the exposed subjects is quite striking, and it should be noted that the intra-familial controls were completely without disease. Our data therefore clearly demonstrate that DES 
exposure during pregnancy is associated with a strikingly high incidence of behavioral and/or psychiatric disorders.

The prevalence of eating disorders in our cohort was eight times higher in the exposed adolescents and young women, as previously shown in a study of Gustavson et al., who reported on 1711 women with an OR of 5.72 (18). Behavioral disorders (11.2\%) were also higher in the exposed population. Depression was four times-, 26.2\%) more prevalent than in the general population, with the DES daughters being more affected than the sons. This observation confirms the epidemiological study from O'Reilly et al. (12). This group reported an OR of 1.47 in a group of 1612 exposed DES daughters. Our data also agree with the findings of Vessey et al. (10), who showed that the offspring of the exposed group -had twice as much anxiety as the offspring of the unexposed group. Several small case-control studies have since confirmed these findings (19-23), all reporting rates of major depressive disorders (MDD) significantly higher than for the general population. Our data illustrate a higher risk of schizophrenia, as this disease was 17 times more prevalent than in the general population, with sons being more affected than DES daughters. To date, there have been few data regarding this association. In 1987, Katz et al. (24) for the first time reported four subjects in a very small cohort suffering from psychosis after DES exposure; in 1993, Pillard et al. (23) observed several subjects in another cohort showing "paranoid ideation" (the diagnostic term today being "paranoid schizophrenia"). More recently, Kebir and Krebs (unpublished data in 13) analyzed the data from a small HHORAGES cohort and noted the high frequency of psychotic disorders but claimed that this finding did not demonstrate any causality between in utero DES exposure and a specific disorder. Nevertheless, these authors also examined three epidemiological studies with worldwide cohorts and several smaller cohorts with the objective of determining the impact of DES on the development of psychiatric disorders, including schizophrenia (13). They found that out of all these studies, only one did not support the hypothesis of a causal link (11). With regard to suicides, our work 
clearly demonstrates a drastically increased risk of suicide attempts $(65.4 \%$ versus 0 in the unexposed controls and $0.25 \%$ in general population) and suicides (3.4\% versus 0 in the unexposed controls and $0.02 \%$ in general population). It could be noted that, as in the general population, DES sons commit more suicides than DES daughters, and inversely for suicide attempts. Moreover, our data reveal that $50 \%$ of the sons who committed suicide suffered from schizophrenia. Psychiatric studies in general have shown that the percentage of suicides is generally higher in individuals with psychiatric disorders than in the general population. But to our knowledge, there is no information or specific studies concerning this association in the context of DES exposure.

Sixteen subjects in Group 3 (post-DES children) (Table 2) had diagnosed psychiatric disorders. An explanation for this finding might be that DES-, being very lipophilic synthetic estrogens, remains in the mothers' fat after estrogenic impregnation in a previous pregnancy and are then released through the placental barrier in the next gestation.

\section{Conclusion}

In conclusion, we demonstrate here that prenatal exposure to DES is associated with psychiatric disorders in adolescence and adulthood. These data have been supported by recent preliminary work by Réseau DES-France suggesting a higher risk of psychiatric disorders in DES daughters, based on an analysis of the data from 3436 DES daughters versus 3256 control women (25). Moreover, in a recent review on the risk of psychiatric disorders in adolescents exposed in utero to DES, Kebir and Krebs (13), in agreement with Abdomalecky et al. (26), noted that the role of prenatal exposure to DES as an environmental factor for psychiatric disorders may involve a gene-environment interaction, as well as an epigenetic mechanism. This latter group reported for the first time that prenatal exposure to DES induced specific modifications in fetal 
DNA methylation that could be involved in postnatal neurodevelopment and the subsequent psychiatric disorders in adolescence (27).

\section{Authors}

Marie-Odile Soyer-Gobillard (mog66@orange.fr)

Centre National de la Recherche Scientifique, Unité Mixte de Recherche 7628 Université P. et M. Curie (Paris6) Laboratoire Arago, F-66650 Banyuls sur mer and Association HHORAGES, (Halte aux HORmones Artificielles pour les GrossessES), Le Prieuré de Baillon, F- 95270 Asnières sur Oise.www.hhorages.com

Charles Sultan (c-sultan@chu-montpellier.fr $)$

Françoise Paris (f.paris@chu-montpellier.fr)

Laura Gaspari (dr.lauragaspari@gmail.com)

Service d'Hormonologie (Développement et Reproduction), Hôpital Lapeyronie, CHU de Montpellier, Montpellier, France et Institut de Génétique Humaine, CNRS UPR 1142, Montpellier, France Service de Pédiatrie I, Unité d'endocrinologie et gynécologie pédiatrique, Hôpital Arnaud-de-Villeneuve, CHU de Montpellier, Montpellier Cedex 5, France

Philippe Courtet (p-courtet@ chu-montpellier.fr)

Département d'Urgence et Post Urgence Psychiatrique, CHU Montpellier \& Université Montpellier, France

\section{Disclaimer}

The authors declare they have no competitive financial interest concerning this paper; HHORAGES-France Association is financed exclusively by donations.

\section{Acknowledgments}

Mr René Alexandre, Dr Henri Pézerat and Prof. Jean Caston have worked tirelessly to demonstrate the harmful role of endocrine disruptors, particularly synthetic hormones, before passing away: we shall never forget their great help. This work could not continue without the daily ongoing support of the HHORAGES board, especially Geneviève Alchourroun, 
Mauricette Puillandre, Denise Hemmerdinger, Michel Datry, Yette Blanchet and Charles Zelwer. We are very grateful to Professor MO Krebs and Dr O Kébir for believing in our hypothesis nine years ago and for working so hard to scientifically demonstrate it.

\section{References}

1-Smith OW. Diethylstilbestrol in the prevention and treatment of complications of pregnancy. Am J Obstetric Gynecol 1948; 56: 821-34.

2- Dieckman WJ, Davis ME, Rynkiewicz LM, Pottinger RE. Does the administration of diethylstilbestrol during pregnancy have therapeutic value? American Journal of Obstetrics and Gynaecology 1953; 66: 1062-1081.

3- Giusti RM, Iwamoto K, Hatch E. Diethylstilbestrol revisited: A review of the long term health effects. Annals of Internal Medicine 1995; 122: 778-788.

4- Newbold RR. Lessons learned from perinatal exposure to diethylstilbestrol. Toxicology and Applied Pharmacology 2004; 199: 142-150.

5- Herbst AL, Ulfelder H, Poskanzer DC. Adenocarcinoma of the vagina. Association of maternal stilboestrol therapy with tumor appearance in young women. New England Journal of Medicine 1971; 284: 878-881.

6- Gill WB, Schumacher GF, Bibbo M, Straus FH 2nd, Schoenberg HW. Association of diethylstilbestrol exposure in utero with cryptorchidism, testicular hypoplasia and semen abnormalities. Journal of Urology 1979; 22(1): 36-39.

7- Palanza, P., Morellini, F., Parmigiani, S., Vom Saal, F.S. Prenatal exposure to endocrine disrupting chemicals: effects on behavioral development. Neuroscience Biobehavioral Review 1999; 23: 1011-1027.

8- Dugard ML, Tremblay-Leveau H, Mellier D, Caston J. Prenatal exposure to ethinylestradiol elicits behavioural abnormalities in the rat. Developmental Brain Research 2001; 129: 189-199.

9- Arabo A, Lefebvre M, Fermanel M, Caston J. Administration of 17-alpha-ethinylestradiol during pregnancy elicits modifications of maternal behaviour and emotional alteration of the offspring in the rat. Developmental Brain Research 2005; 156: 93- 103.

10- Vessey MP, Faiweather DV, Norman-Smith B, Buckley J. A randomized double-blind controlled trial of the value of stilboestrol therapy in pregnancy: long term follow-up of mothers and their offspring. British Journal of Obstetrics and Gynaecology 1983; 90:1007-1017.

11- Verdoux H, Ropers J, Costagliola D, Clavel-Chapelon F, Paoletti X. Serious psychiatric outcome of subjects prenatally exposed to diethylstilbestrol in the E3N cohort study. 
Psychological Medicine 2007; 37: 1315-1322.

12- O'Reilly EJ, Mirzaei F, Forman MR, Ascherio A. Diethylstilbestrol exposure in utero and depression in women. American Journal of Epidemiology 2010; 171: 876-882.

13- Kebir O, Krebs MO. Diethylstilbestrol and risk of psychiatric disorders: A critical review and new insights. The World Journal of Biological Psychiatry 2012; 13(2): 84-95.

14- Nicoli M, Bouchez I, Nieto I, Kovess V, Lepine JP. Ideation et conduites suicidaires en France: prevalence sur la vie et facteurs de risque dans l'étude ESEMeD. L'Encéphale 2012; 38: 296-303.

15- Lépine JP, Gasquet V, Kovess V, Arbabzadeh-Bouchez S, Nègre-Pages L, Nachbaur G, Gaudin AF. Prévalence et comorbidité des troubles psychiatriques dans la population générale française: résultats de l'étude épidémiologique ESEMeD/MHEDEA 2000/(ESEMeD). L'Encéphale 2005; 31: 182-194

16-Turusov VS, Trukhanova LS, Parfenov Yu D, Tomatis L. Occurrence of tumors in the descendants of CBA male mice prenatally treated with diethylstilbestrol. International Journal of Cancer 1992; 50: 131-135.

17-Walker BE, Haven MI. Intensity of multigenerational carcinogenesis from diethylstilbestrol in mice. Carcinogenesis 1997; 18, 791-793.

18- Gustavson CR, Gustavson JC, Noller KL, O’Brien PC, Melton LJ, Pumariega AJ et al. Increased risk of profound weight loss among women exposed to diethylstilbestrol in utero. Behavioural Neural Biol 1991; 55: 307-312.

19- Meyer-Bahlburg HF, Ehrhardt AA, Endicott J, Veridiano NP, Whitehead ED, Vann FH. Depression $n$ adults with a history of prenatal DES exposure. Psychopharmaceutical Bulletin 1985; 21: 686-689.

20- Meyer-Bahlburg HF, Ehrhardt AA. A prenatal-hormone hypothesis for depression in adults with history of fetal DES exposure. In: Halbreich U, ed. Hormones and depression. New York: Raven Press. 1987; p. 325-338.

21- Ehrhardt AA, Feldman JF, Rosen LR, Meyer-Bahlburg HF, Gruen R, Veridiano NP, et al. Psychopathology in prenatally DES-exposed females: current and lifetime adjustment. Psychosomatic Medicine 1987; 49: 183-196.

22- Fried-Cassorla M, Scholl TO, Borow LD, Strassman HD, Bowers EJ. Depression and diethylstilbestrol exposure in women. J Reprod Med 1987; 32: 847-850.

23- Pillard RC, Rosen LR, Meyer-Bahlburg H, Weinrich JD, Feldman JF, Gruen R et al. Psychopathology and social functioning in men prenatally exposed to diethylstilbestrol (DES). Psychosomaric Medicine 1993; 55: 485-491. 
24- Katz DL, Frankenburg FR, Benowitz LI, Gilbert JM. Psychosis and prenatal exposure to diethylstilbestrol. J Nerv Ment Dis 1987; 175:306-308.

25-Distilbène, Etude sur trois générations. Résultats préliminaires, Réseau DES-France; 2014. $4 \mathrm{p}$.

26-Abdolmaleky HM, Smith, CL, Faraone SV, Shafa R, StoneW, Glatt, SJ and Tsuang MT. Methylomics in psychiatry: modulation of gene-environment interactions may be through DNA methylation. American Journal of Medicine Genetics B Neuropsychiatric Genetics 2004; 127, 51-59

27- Rivollier F. Exposition prénatale aux Perturbateurs Endocriniens et risque sur le neurodéveloppement: Etude de fratries exposées au Diéthylstilbestrol. Thèse de Doctorat d'Etat en Médecine, Université Paris Descartes, soutenue le 6 février 2015, 97pp. (Unpublished data).

\section{Legends:}




\section{Tables:}

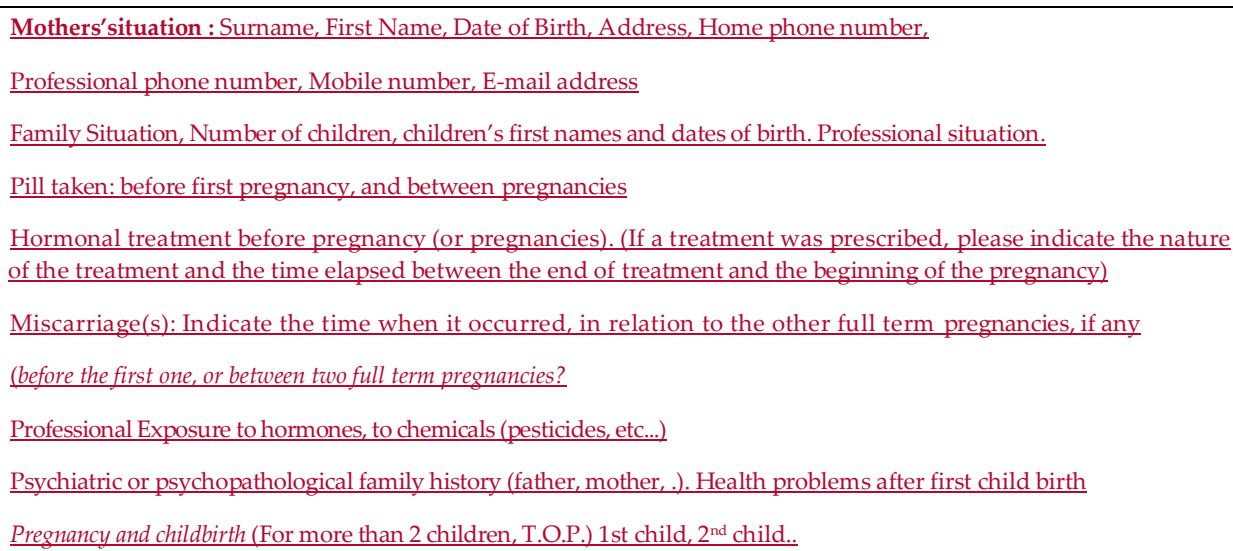

What medical reason was put forward (possible miscarriage, comfort, etc...)? At what month did the delivery occur, from the start of the pregnancy?

General condition of the child, Sex, Weight, Health problems at birth (mother and child) Existing documents (prescriptions, medical files, etc...) and testimonies

Would you be so kind as to send us the copies of the files and documents? If yes, in order to save time, please attach the copies of all relative documents in your possession.

Heal th problems of your children (For more than 2 children, T.OP)

1st child, 2nd child First name, Sex, Birth Date, Rank in the sibling order Physical disorders: Which ones? What age? Sterility treatment? Surgery?

Psychological disorders: Nature of first symptoms? What age? Subsequent aggravation? And at what age?

Other data: Hospitalization, Violence, Suicide attempt(s), Medical Treatments, Diagnosis, AAH, Disability?

Relational difficulties: in married life, in professional life?

Children, grandchildren: How many? Full term? Health condition? Malformations or observed disorders?

Table 1. Questionnaire sent to families. 


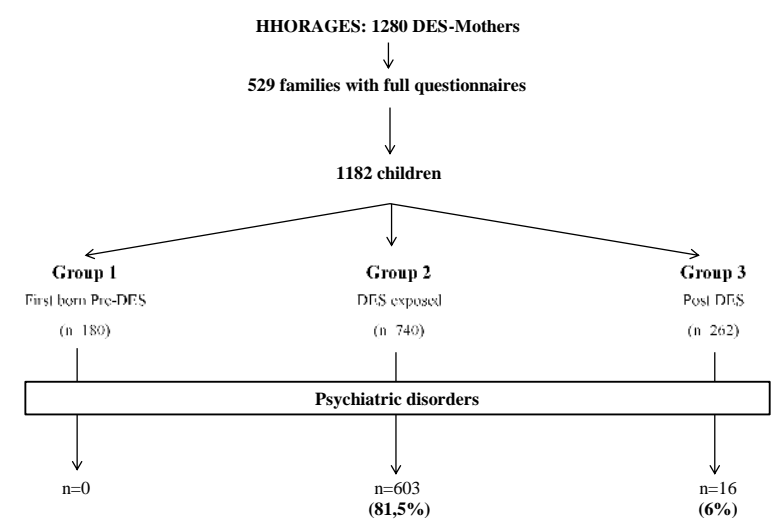

Table 2

Table 2. Classification of the three groups of the HHORAGES cohort.

Table 3:

Among the 1002 DES exposed (Gpe 2) post exposed (Gpe 3) adolescents:

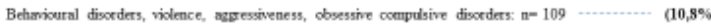

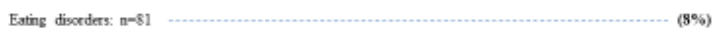

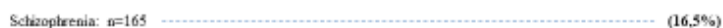

Depression, bipolix dsorder, anciety. n-248 $\cdots \cdots$

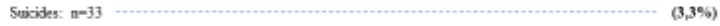

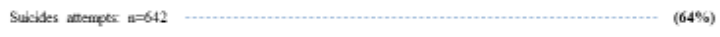

Talbe 3

Table 3: Total number of psychological/psychiatric disorders among the 982 (1002-20 stillborn) DESexposed and post-DES children. 
Table 4:

\begin{tabular}{|c|c|c|c|c|}
\hline & $\begin{array}{c}\text { Group } 2 \\
\text { DES expoged }\end{array}$ & $\begin{array}{l}\text { Group } 3 \\
\text { Poot DES }\end{array}$ & $\begin{array}{c}\text { Group 1 } \\
\text { Frst bom Pre-DES (cortrols) }\end{array}$ & $\begin{array}{c}\text { General } \\
\text { population }\end{array}$ \\
\hline & $(\mathrm{m}=740)$ & $(\mathrm{m}=262)$ & $(\mathrm{m}=180)$ & \\
\hline Behavivural dsorders & $(14,7 \%)$ & $(0,38 \%)$ & $(0 \%)$ & (3\%) \\
\hline Exting dsorders & $(10,9 \%)$ & $(0,76 \%)$ & $(0 \%)$ & $(0,6 \%)$ \\
\hline Schiboptrenia & $(21,5 \%)$ & $(2,3 \%)$ & $(0 \%)$ & (1\%) \\
\hline Depression & $(32,3 \% 6)$ & $(3,4 \%)$ & $(0 \%)$ & $(6,3 \%)$ \\
\hline \multicolumn{5}{|l|}{ Suicides: } \\
\hline - attentints & $(82,7 \% 6)$ & $(18,5 \% 9)$ & $(0 \%)$ & $(0,25 \%)$ \\
\hline -deash & $(4,3 \%)$ & $(0,6 \%)$ & $(006)$ & $(0,02 \%)$ \\
\hline
\end{tabular}

Table 4: Prevalence of the psychological and/or psychiatric disorders and comparison with the general population. 
